\title{
Inflammation in COPD: a link to systemic comorbidities
}

\author{
S.I. Rennard
}

ABSTRACT: Chronic obstructive pulmonary disease (COPD) has been defined as a preventable and treatable disease characterised by progressive airflow limitation that is not fully reversible and associated with an abnormal inflammatory response in the lungs.

Results from a large number of recent studies have characterised the inflammatory processes underlying COPD. Inflammatory cells, most notably CD8+ T-lymphocytes, macrophages and neutrophils, as well as a large number of chemokines, cytokines and proteinases, are believed to play a role.

The inflammatory processes in COPD contribute to remodelling of pulmonary tissues, leading to the irreversible airflow limitation characteristic of this disease. Inflammation may also contribute to the comorbidities often observed in COPD patients. Patients with COPD often have cardiovascular disease, changes in body composition, osteoporosis and anaemia. The same inflammatory processes that characterise COPD are also risk factors for these comorbidities.

Ongoing studies are evaluating a wide range of new therapies for chronic obstructive pulmonary disease. Some of these have the potential to blunt the inflammatory processes underlying chronic obstructive pulmonary disease and potentially the associated comorbid conditions. These therapies may significantly improve survival, function and quality of life for patients with this disease.

KEYWORDS: Chronic obstructive pulmonary disease, inflammation, respiratory disease, smoking cessation, systemic disease, systemic inflammation

$\mathbf{T}$ he most recent update of the Global Initiative for Chronic Obstructive Lung Disease (GOLD) [1, 2] defines chronic obstructive pulmonary disease (COPD) as: "a preventable and treatable disease with some significant extrapulmonary effects that may contribute to the symptom characterised by airflow limitation that is not fully reversible. The airflow limitation is usually progressive and associated with an abnormal inflammatory response of the lung to noxious particles or gases." COPD has traditionally been regarded as a disease of the pulmonary system, characterised by irreversible airflow limitation due to chronic bronchitis and/ or emphysema. This definition, however, emphasises the importance of the inflammatory processes present in COPD. This provides a mechanistic link among multiple organs leading to the complex interacting systemic manifestations that account for most of the considerable morbidity and mortality in COPD patients [3-5].

COPD is the fifth leading cause of death worldwide [6]. However, until recently, COPD has not received attention from the medical or research communities commensurate with its impact on worldwide health. This may be due, at least in part, to the fact that the aetiology of COPD is closely linked to smoking, and smoking cessation has been viewed as the only treatment that can significantly alter disease progression in most patients with this condition. The direct causal relationship between tobacco smoke and COPD is well established [7], as are the benefits of smoking cessation [3, 4, 8]. As a result, there appears to be a perception that COPD is selfinflicted. Nevertheless, not all smokers develop COPD and $\sim 20 \%$ of patients with this disease are nonsmokers $[9,10]$. One of the key goals of COPD research has been to determine whether there are any pathogenetic features of smoking-related inflammation that distinguish "susceptible" smokers who develop COPD from those who do not. Individuals at risk for smoke-induced lung disease are also at increased risk for other diseases associated with smoking that are often comorbid conditions in COPD patients.

The present article provides an overview of the pulmonary inflammatory response to tobacco smoke, focusing on selected key studies that have helped to clarify the link between smoking,
CORRESPONDENCE

S.I. Rennard

University of Nebraska Medical Center

985885 Nebraska Medical Center Omaha

NE 68198-5885

USA

Fax: 1402559487

E-mail: srennard@unmc.edu

STATEMENT OF INTEREST

S.I. Rennard has been reimbursed for attending a symposium and has participated as a speaker at programmes organised by AstraZeneca, Boehringer Ingelheim, GlaxoSmithKline, Otsuka and Pfizer. He serves on advisory boards for Altana, AstraZeneca, Dey, GlaxoSmithKline, Novartis, ScheringPlough and Talecris. S.I. Rennard has conducted clinical trials for Almirall, Altana, Astellas, Centocor, GlaxoSmithKline, Nabi, Novartis and Pfizer. He has also served as a consultant for Adams, Almirall, Altana, AstraZeneca, Bend, Biolipix, Centocor, Critical Therapeutics, GlaxoSmithKline, ICOS, Johnson \& Johnson, Novartis, Ono, Parengenix, Pfizer, Roche, Sankyo, Sanofi and Schering-Plough. A patent is pending on a method for stem cell differentiation; S.I. Rennard is a coinventor of the patent owned by the University of Nebraska Medical Center. 
inflammation and COPD, and considers the role of systemic inflammation in the pathogenesis of comorbidities observed in many patients with COPD.

\section{INFLAMMATION IN COPD}

Inflammation is believed to play a central role in the pathogenesis of COPD [11]. Cigarette smoking is associated with both inflammation of the lower respiratory tract and with evidence of systemic inflammation. The major alteration in the lungs of young smokers is a marked increase in alveolar macrophages. These cells accumulate pigment particles, and their state of activation and gene expression is altered. With smoking cessation, however, this change may be reversible. As smokers are variably sensitive to developing COPD, it is unclear if these changes reflect the pathogenesis of disease or an adaptive host defence. As COPD develops, the major cell types present are macrophages, neutrophils and CD8+ lymphocytes, although eosinophils may also be present in some individuals, particularly during exacerbations.

\section{CD8+ T-LYMPHOCYTES}

There are significant differences in CD8+ T-lymphocyte profiles in the peripheral and central airways of smokers with and without COPD [12-14]. It is likely that the peripheral airways are the site of airflow obstruction in many individuals with COPD. In this context, SAETTA et al. [14] examined surgical specimens from two groups of smokers undergoing lung resection for localised pulmonary lesions. One group was asymptomatic and had normal lung function while the other had symptoms of chronic bronchitis and mild chronic airflow limitation (i.e. COPD). Immunohistochemical methods were used to identify neutrophils, macrophages and CD4+ and CD8+ T-lymphocytes infiltrating the airway wall. Morphometry was employed to measure the internal perimeter, airway wall and smooth muscle area in peripheral airways. Smokers with COPD had increased smooth muscle mass suggesting the presence of airway remodelling and an increased number of CD8+ T-lymphocytes (fig. 1) compared with smokers without COPD. Other inflammatory cell types, including neutrophils,

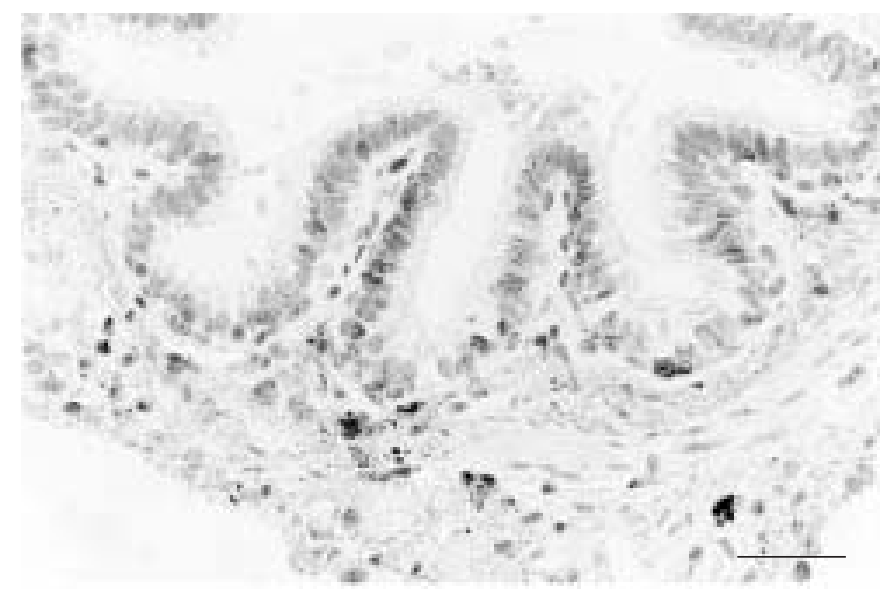

FIGURE 1. Photomicrograph showing CD8+ T-lymphocyte infiltration in a peripheral airway of a smoker with symptoms of chronic bronchitis and mild chronic airflow limitation. Anti-CD8 antibody was used for immunostaining. Scale bar $=50 \mu \mathrm{m}$. Reproduced from [15] with permission from the publisher. assessed in the airway tissues were comparable between the two groups.

Similar changes were observed by O'SHAUGHNESSY et al. [13] in the large airways, in bronchial biopsies from five normal nonsmokers without chronic bronchitis, in 11 smokers with chronic bronchitis but without airflow limitation, and in 13 smokers with chronic bronchitis and airflow limitation (i.e. COPD). Increased numbers of CD8+ T-lymphocytes were observed in the subjects with COPD, and there was a correlation between the number of CD8+ T-lymphocytes and the degree of airflow limitation. Similar observations were made in a study by Di STEFANO et al. [12] of 24 subjects assessed by bronchial biopsy. Since the large airways are not likely to be the major site of airflow limitation, the relationship observed between forced expiratory volume in one second (FEV1) and increased numbers of CD8 lymphocytes suggests that the inflammatory response is more generalised. Consistent with this increase, in a study by SAETTA et al. [15], CD8 lymphocytes were reported in both the alveolar wall and the pulmonary arteries.

PEINADO et al. [16] confirmed the increased numbers of CD8 lymphocytes in pulmonary arteries. Importantly, they extended these observations by evaluating the endotheliumdependent relaxation in the pulmonary arteries in the following three groups of patients who were undergoing lung resection: nonsmokers, smokers with normal lung function and smokers with COPD. In the COPD subjects, the pulmonary arteries developed a lower degree of relaxation in response to adenosine diphosphate compared with either the nonsmokers or the smokers with normal lung function. The COPD patients in this study also had increased numbers of inflammatory cells (specifically T-lymphocytes) in their pulmonary arteries. Although potential mechanisms are not established, the intensity of the inflammatory infiltrate correlated with both endothelium-dependent relaxation and intimal thickness. Moreover, the CD8+ T-lymphocyte subset was increased not just in COPD patients but also in the group of smokers with normal lung function, leading to a reduction of the CD4+/ CD8+ ratio (fig. 2). The relationship between CD8+ T-lymphocyte infiltration in smokers and impairment of arterial structure and function suggests the possibility that CD8+ T-lymphocytes play a role early in the pathogenesis of pulmonary vascular abnormalities that may occur in the early stages of COPD (fig. 3).

\section{AIRWAY NEUTROPHILS}

Neutrophils are also present in increased numbers and are related to disease severity in COPD (fig. 3). In an early study, THOMPSON et al. [17] used bronchoalveolar lavage (BAL) and bronchoscopy to characterise intraluminal airway inflammation in 28 patients with chronic bronchitis and fixed airway obstruction, 15 asymptomatic smokers and 25 healthy nonsmoking volunteers. Evidence of inflammation was greater among the chronic bronchitis patients, and the BAL fluid from these individuals contained a higher percentage of neutrophils $(35.8 \%)$ than the BAL fluid from either the asymptomatic smokers $(20.7 \%)$ or the nonsmokers $(10.3 \%)$. Chronic bronchitis patients with significant percentages of neutrophils $(>20 \%)$ in BAL fluids had significantly more sputum production and lower FEV1 values than patients with a lower percentage of 

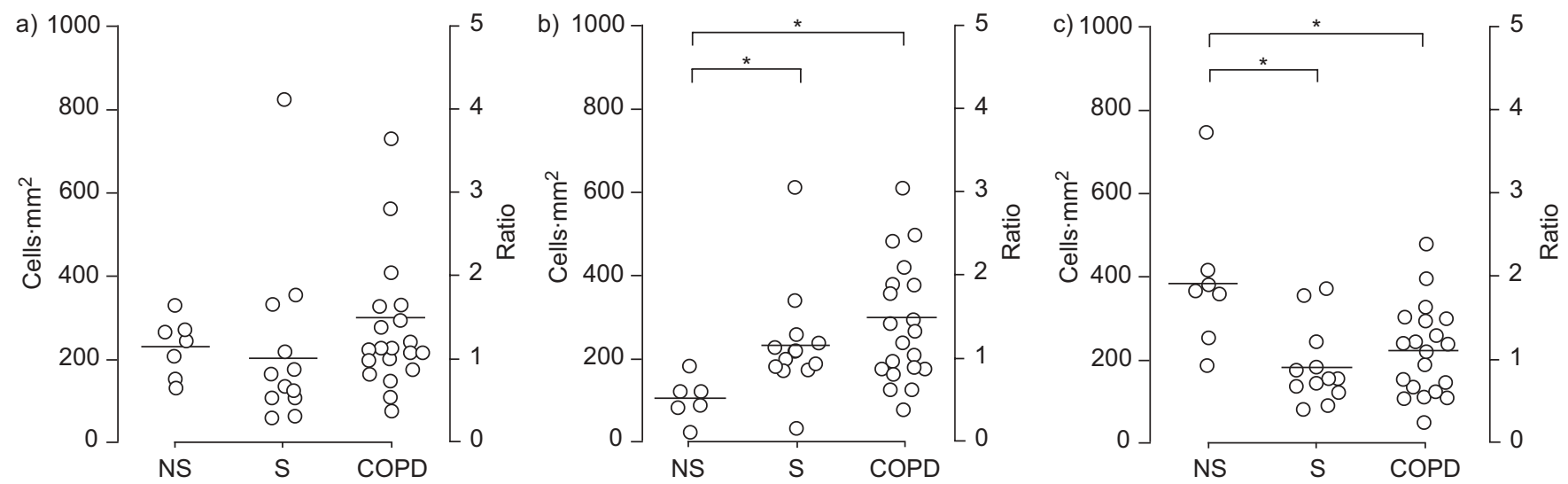

FIGURE 2. Counts of a) CD4+, b) CD8+ and c) CD4+/CD8+ T-lymphocytes in pulmonary artery specimens from nonsmokers (NS), smokers with normal lung function (S) and chronic obstructive pulmonary disease (COPD) patients. Reproduced and modified from [16] with permission from the publisher. ${ }^{*}: p<0.05$.

neutrophils $(<20 \%)$. The link between neutrophils and smoking is underscored by results showing that the percentage of neutrophils in BAL fluid is highly correlated with the cigarette smoking history in both pack-yrs $\left(\mathrm{r}^{2}=0.65\right)$ and number of cigarettes smoked per day $\left(\mathrm{r}^{2}=0.41\right)$ [17].

In the subsequent study by Di STEFANO et al. [12], no difference in neutrophils between those with and without airflow limitation was observed. However, THOMPSON et al. [17] assessed intraluminal inflammation using BAL, while DI STEFANO et al. [12] assessed airway wall neutrophils, indicating that the neutrophilic inflammation of the two compartments may differ. In this context, the accumulation of neutrophils in airway glands has been suggested to contribute to mucus hypersecretion [18]. Several subsequent studies, including both BAL and sputum analyses, have confirmed the presence of increased intraluminal neutrophils in COPD. Interestingly, subsequent studies have suggested that tissue neutrophils [19] also increase as disease severity worsens (fig. 3).

With exacerbations, neutrophilic inflammation is likely to increase. In a biopsy study of 11 patients with chronic bronchitis examined during an exacerbation, higher numbers of neutrophils were observed than in 12 individuals with stable chronic bronchitis [20]. Similar increases in intraluminal neutrophils during exacerbations have been observed in sputum specimens.

\section{SMOKING CESSATION AND PULMONARY INFLAMMATION}

The Lung Health Study (LHS) demonstrated that smoking cessation early in the course of COPD can slow the rate at which lung function is lost. The LHS was a randomised clinical trial of smoking cessation and regular administration of an inhaled bronchodilator in 5,887 middle-aged smokers who had mild COPD [21]. Participants in the LHS were randomised to one of the following three groups: 1) smoking intervention (i.e. an intensive smoking cessation programme with a continuing 5 -yr maintenance programme to prevent relapse) plus bronchodilator; 2) smoking intervention (as above) plus placebo; and 3) usual care. After 5 yrs, smoking cessation significantly reduced the rate of decline in lung function. The use of a bronchodilator resulted only in a small improvement in FEV1, which was immediately reversed after the drug was discontinued. A follow-up study performed 11 yrs after the LHS entry included 4,527 of the surviving participants. Most (93\%) of these participants who abstained from smoking throughout the initial 5-yr study period remained abstinent at 11 yrs. The benefits of cessation were even clearer: quitters had smaller declines in FEV1 than continuing smokers (fig. 4). At 11 yrs, $38 \%$ of continuing smokers had an FEV1 value $<60 \%$ of the predicted normal value versus $10 \%$ of the sustained quitters [3].

As might be expected, smoking cessation is associated with a reduction in lower respiratory tract inflammation in "normal" smokers. SKOLD et al. [22] performed BAL in smokers before cessation and at 1, 3, 6, 9 and 15 months after quitting. After smoking cessation, total recovered macrophages were decreased after 1 month and had returned to normal levels by 6 months. The autofluorescence characteristic of smokers' macrophages, which presumably reflects engulfed particles, remained elevated for 15 months. A similar change in inflammatory cells following smoking cessation was observed in sputum of normal smokers by SWAN et al. [23].

In patients with COPD, however, inflammation may not resolve as readily. In a cross-sectional study, TURATO et al. [24] assessed endobronchial biopsies in nine current and seven former smokers who had quit, on average, 13 yrs earlier. There were no differences in numbers of airway neutrophils, total lymphocytes, CD4 or CD8 lymphocytes, macrophages or for any other parameter assessed. While this was a small study, RUTGERS et al. [25] provided more evidence for the persistence of inflammatory cells after smoking cessation in COPD in another cross-sectional study that evaluated 18 COPD patients (three nonsmokers and 15 ex-smokers, all with bronchitis) and 11 nonsmoking healthy controls. Participants with COPD, who did not currently smoke, had persistent airway inflammation that was reflected by significantly increased mucosal macrophage and eosinophil numbers, elevated sputum neutrophil and eosinophil percentages, and higher BAL fluid eosinophil percentages compared with healthy controls. In a larger crosssectional study of 114 subjects, LAPPERRE et al. [26] stratified subjects based on whether they were smokers, or had quit more or less than 3.5 yrs earlier. Compared with current smokers, ex-smokers had higher numbers of total lymphocytes, 

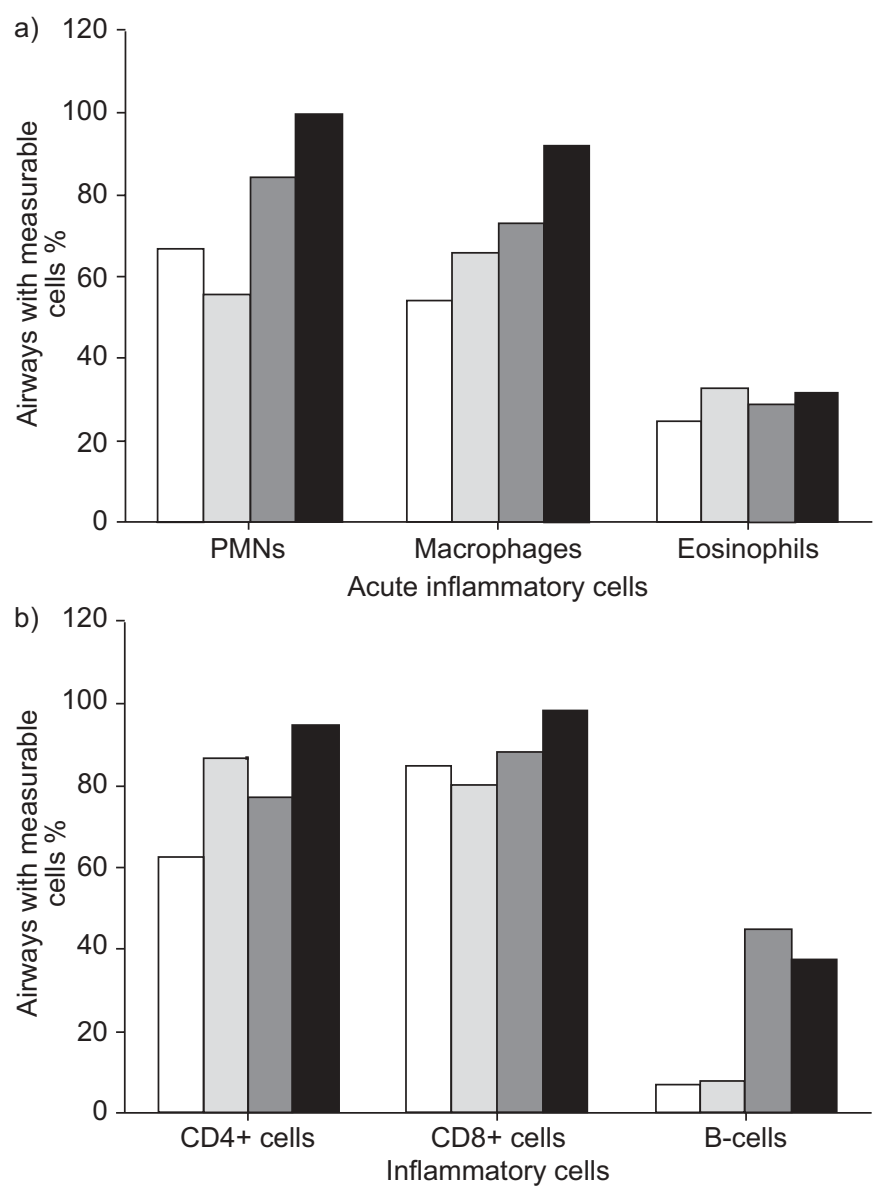

FIGURE 3. Clinical findings in patients with chronic obstructive pulmonary disease according to the Global Initiative for Chronic Obstructive Lung Disease (GOLD) stage. a) Extent of airway inflammatory response as measured by the percentage of airways containing polymorphonuclear neutrophils (PMNs), macrophages and eosinophils; b) similar data for CD4+ T-lymphocytes, CD8+ Tlymphocytes and B-cells. $\square$ : GOLD stage 0; 1 : GOLD stage 1; $\mathbf{~ : ~ G O L D ~ s t a g e ~ 2 ; ~}$ 口: GOLD stage 3. Reproduced from [19] with permission from the publisher.

CD4+ lymphocytes and plasma cells in endobronchial biopsy specimens. CD8+ lymphocytes, in contrast, were reduced in the long-term ex-smokers.

Cross-sectional studies of former smokers with COPD have a number of potential biases, including the reasons for cessation and the persistence of symptoms despite cessation. Importantly, WILLEMSE et al. [27] have evaluated the effect of smoking cessation prospectively. In 12 patients with COPD who successfully quit, there were increases in sputum neutrophils, lymphocytes and interleukin (IL)-8. In addition, while the differences did not reach statistical significance, there were trends toward increased inflammation assessed by endobronchial biopsy. These findings are in contrast with 16 asymptomatic smokers who quit and in whom inflammatory parameters were either unchanged or decreased. A similar failure for inflammation to resolve in a prospective smoking cessation study has been reported by SPURZEM et al. [28].

While the available data are limited, they are consistent with the concept that smoking initiates an inflammatory response in a)
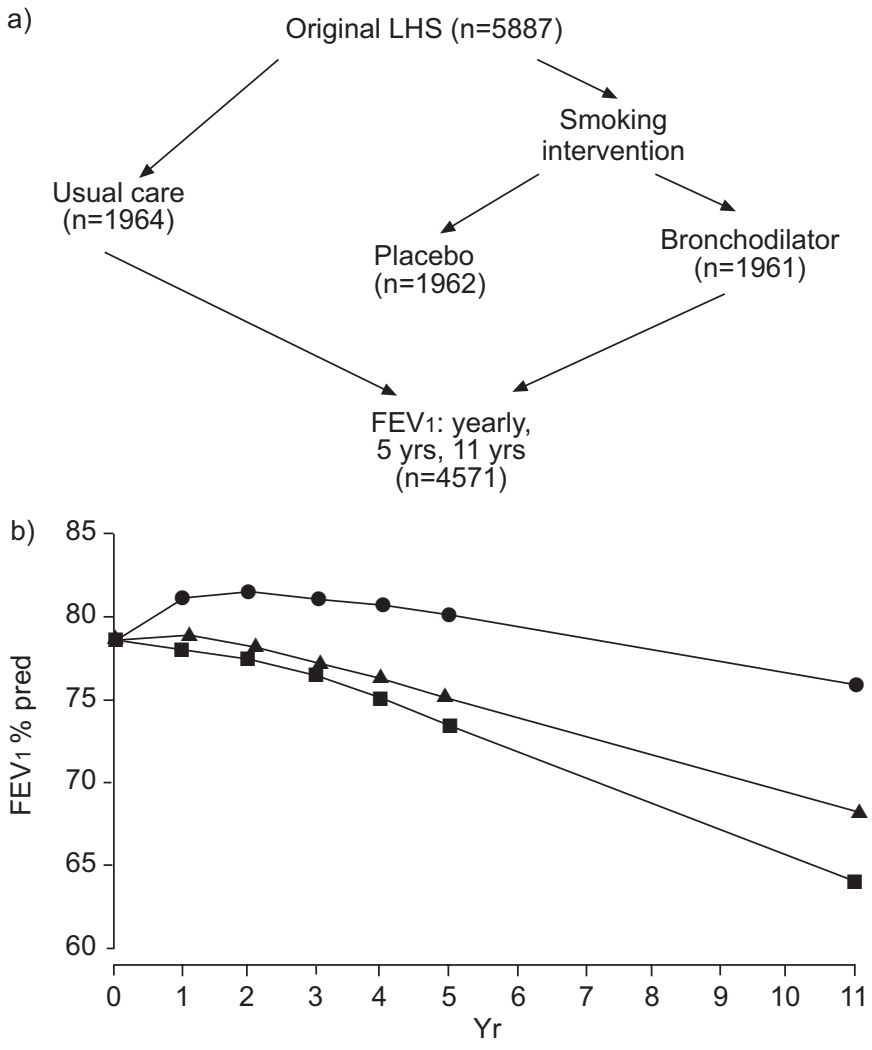

FIGURE 4. a) Loss of lung function over the years of the Lung Health Study (LHS) among sustained quitters, continuing smokers and intermittent smokers. b) Mean values of postbronchodilator forced expiratory volume in one second (FEV1) values are shown, expressed as a percentage of the predicted normal value $(\%$ pred). $\mathbf{\square}$ : smokers; $\mathbf{\Lambda}$ : intermittent; $\bullet$ : quitters. Reproduced and modified from [3] with permission from the publisher.

the lung. Cessation early enough can lead to reversal of this inflammation, although it may take many months for normalisation. However, once COPD is established, inflammation can persist. Following cessation, there may be an evolution of the inflammatory response that may include an initial increase in some inflammatory measures and a long-term decline in other measures. These temporal changes remain to be defined, as do their functional significance. Nevertheless, the persistence of inflammation following smoking cessation is consistent with the concept that systemic effects of COPD may be a result of inflammation, even in the ex-smoking COPD patient.

\section{SYSTEMIC CONSEQUENCES LINKED TO SYSTEMIC INFLAMMATION}

COPD is often associated with clinical manifestations that include metabolic abnormalities, weight loss, muscle weakness and wasting, cardiovascular disease (e.g. atherothrombosis, ischaemic heart disease, stroke and coronary death), depression, osteoporosis, cancer and anaemia [29]. There is a rapidly growing body of evidence indicating that the pulmonary disease observed in patients with COPD is also associated with systemic inflammation [30]. GAN et al. [30] reviewed 14 original studies that reported on the relationship between COPD, FEV1 (or forced vital capacity) and levels of various systemic 

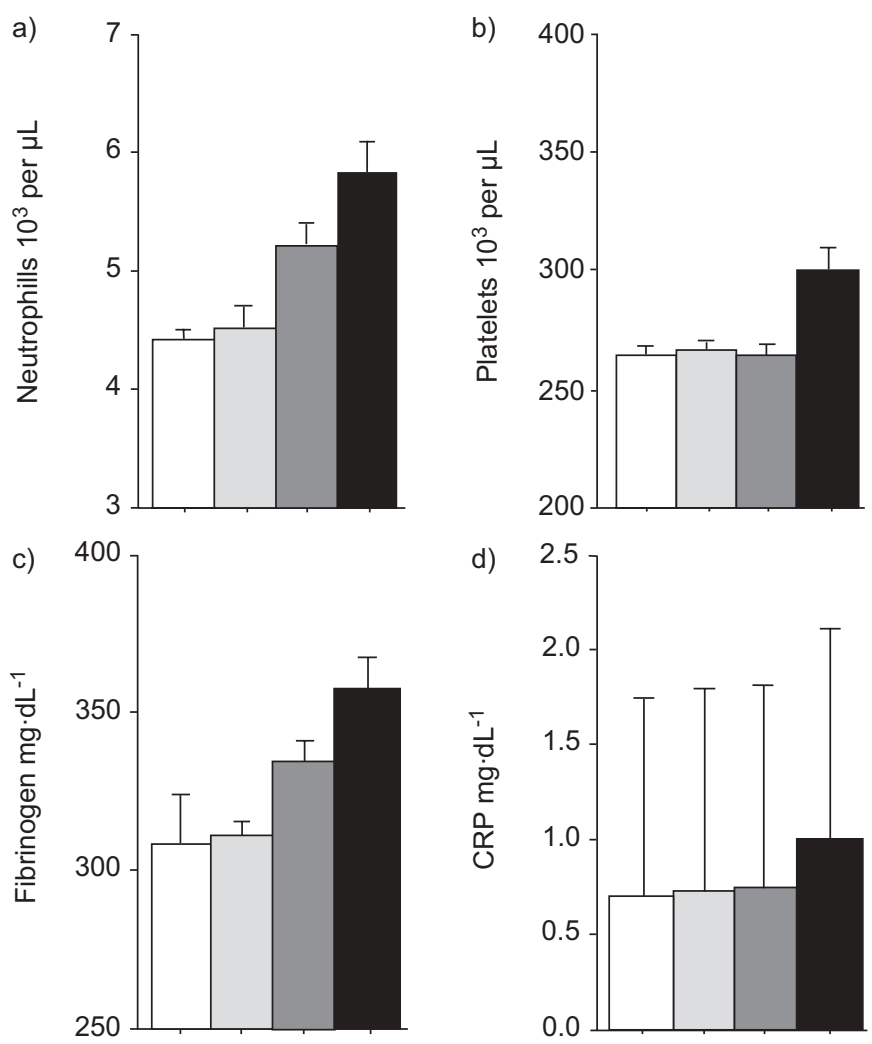

FIGURE 5. Circulating serum inflammatory markers, a) neutrophils, b) platelets, c) fibrinogen and d) C-reactive protein (CRP), in patients with chronic airflow obstruction according to degree of airflow obstruction. $\square$ : normal chronic obstructive pulmonary disease severity; $\mathbf{1}$ : stage 1 ; $\mathbf{m}$ : stage 2; $\mathbf{\square}$ : stages 3-4. Values have been adjusted for age, sex, body mass index, smoking status, race and comorbidity. Data taken from [19].

inflammatory markers, namely C-reactive protein (CRP), fibrinogen, leukocytes, tumour necrosis factor (TNF)- $\alpha$, and IL-6 and -8. This analysis indicated that reduced lung function was significantly correlated with elevated levels of systemic inflammatory markers. A subsequent study carried out by the same group indicated that both active smoking and reduced FEV1 independently contribute to increased levels of systemic inflammatory markers, consistent with the concept described previously that smoking cessation may not fully attenuate the systemic inflammatory processes underlying COPD [31].

Many of the systemic comorbidities associated with COPD have been related to systemic inflammation. The relationship between COPD, systemic inflammation and cardiovascular disease is of particular importance, since more than one-half of all patients with COPD die from cardiovascular causes [21, 30, 32]. Airflow limitation increases the risk of cardiovascular mortality, and this relationship is present across all levels of lung function, even in the "normal range". An FEV1 of $90 \%$ pred, for example, is associated with a three-fold increased risk of myocardial infarction or cardiac death compared with an FEV1 of $110 \%$ pred [33]. Interestingly, this relationship was present in both smokers and nonsmokers. Lung function, in fact, is a better predictor of all-cause and cardiac-specific mortality than many established risk factors, including serum cholesterol $[34,35]$.
The concept that systemic inflammation is the mechanistic link between reduced lung function and cardiac risk is appealing. SIN and MAN [36] analysed data from 6,629 participants in the Third National Health and Nutrition Examination Survey to determine whether CRP and other systemic inflammatory markers were present in those with chronic airflow obstruction and whether or not they were associated with cardiac disease. Individuals with severe airflow obstruction had circulating neutrophil, platelet, fibrinogen and CRP levels that were markedly higher than those in participants without airflow obstruction (fig. 5), and the relationships between lung function and the systemic inflammatory markers was statistically significant. Moderate and severe airflow obstruction were both associated with increased occurrence of ischaemic electrocardiographic changes. Subjects with highly elevated CRP levels and moderate or severe airflow obstruction had cardiac infarction injury scores that were 2.68 and $5.88 \mathrm{U}$ higher, respectively, than in those in subjects without airflow obstruction and with low CRP levels. These results raise the possibility that inflammation reflected by elevated CRP levels and impaired pulmonary function may be independently related to the risk for cardiac disease.

Systemic inflammation may also contribute to the changes in muscle mass and strength that characterise COPD patients. EID et al. [37] have demonstrated an association between body composition and the inflammatory response in stable COPD patients. Individuals with a normal body mass index (BMI)/ low creatinine-height index $(\mathrm{CHI}$; a measure that reflects skeletal muscle mass), as well as those with a low BMI/low CHI, had higher levels of IL- 6 and TNF- $\alpha$ than subjects with a normal BMI/normal CHI. A more recent study involving 102 individuals with severe to very severe COPD confirmed that reduced FEV1 was associated with systemic inflammation, as reflected by increased plasma levels of IL-6 and CRP. Importantly, elevated CRP was also associated with reduced muscle strength, with decreased exercise endurance, shorter 6min walk distance and poor health status [38]. Inflammationassociated oxidative stress leading to skeletal muscle dysfunction, apoptosis and wasting has been suggested to account for the relationship between inflammation and loss of lean body mass in patients with COPD [39].

\section{REPAIR PROCESSES}

The anatomical changes that characterise COPD result not only from tissue destruction but also from abnormal tissue repair [40]. Deficient repair of alveolar structures, for example, is likely to contribute to the development of emphysema [41, 42]. Similarly, overexuberant repair may contribute to the peribronchial fibrosis that results in airway narrowing and also contributes to airflow limitation [19]. In this context, repair should be regarded as an integral part of the inflammatory process. It is likely, therefore, that the abnormal repair present in COPD results, at least in part, as a consequence of the pathological inflammation. Supporting this concept are a number of studies that demonstrate that inflammatory mediators can modulate mesenchymal cell, epithelial cell and endothelial cell repair responses.

It seems likely that many of the systemic morbidities associated with COPD are also processes of abnormal repair. For example, the loss of bone that characterises osteoporosis, 
resembles emphysema in that both represent an imbalance between tissue destruction and tissue renewal. Similarly, the accumulation of mesenchymal cells and connective tissue in atherosclerosis resembles, in some respects, the peribronchial fibrosis of COPD. To what degree these systemic associations of COPD reflect consequences of the systemic inflammation remains to be determined, but a mechanistic link seems plausible.

\section{CONCLUSION}

Although current knowledge about the pathogenesis of chronic obstructive pulmonary disease is expanding rapidly, there is still considerable room for improvement in chronic obstructive pulmonary disease management in order to optimise patient outcomes. It is now well established that noxious substances, such as tobacco smoke, can set off a cascade of inflammatory events in the lungs, involving many types of inflammatory cells and mediators. This can lead to tissue injury, which, together with ineffective repair, can cause changes in structure that compromise airflow. Importantly, pulmonary inflammation, once established in patients with chronic obstructive pulmonary disease, may be independent of cigarette smoking. Pulmonary inflammation, moreover, appears to be correlated with systemic inflammation. This, in turn, is thought to contribute to the development of chronic obstructive pulmonary disease comorbidities, such as cardiovascular disease, which are a major source of morbidity and mortality in chronic obstructive pulmonary disease patients. Current and future research will help to clarify whether attenuation of this systemic inflammation will occur with new chronic obstructive pulmonary disease therapies and whether targeting inflammation in the lung will reduce the risk for comorbidities in chronic obstructive pulmonary disease patients. However, the limited evidence available raises the possibility that medications that blunt the systemic and pulmonary inflammatory processes underlying chronic obstructive pulmonary disease and comorbid conditions have the potential to improve survival, function and quality of life for patients with this disease.

\section{REFERENCES}

1 Celli BR, MacNee W. Standards for the diagnosis and treatment of patients with COPD: a summary of the ATS/ ERS position paper. Eur Respir J 2004; 23: 932-946.

2 Global Strategy for Diagnosis, Management and Prevention of COPD, 2006. www.goldcopd.com. Date last updated: November 2006. Date last accessed: December 2006.

3 Anthonisen NR, Connett JE, Murray RP. Smoking and lung function of Lung Health Study participants after 11 years. Am J Respir Crit Care Med 2002; 166: 675-679.

4 Anthonisen NR, Skeans MA, Wise RA, Manfreda J, Kanner RE, Connett JE. The effects of a smoking cessation intervention on 14.5-year mortality: a randomized clinical trial. Ann Intern Med 2005; 142: 233-239.

5 Sin DD, Man SF. Skeletal muscle weakness, reduced exercise tolerance, and COPD: is systemic inflammation the missing link? Thorax 2006; 61: 1-3.

6 World Health Organization. The World Health Report 2002 - Reducing risks, promoting healthy life. www. who.int/whr/2002/en/. Date last accessed: June 21, 2007.
7 The Health Consequences of smoking: a report of the Surgeon General. Department of Health and Human Services, Centers for Disease Control and Prevention, National Center for Chronic Disease Prevention and Health Promotion. Office on Smoking and Health, Washington, 2004.

8 US Department of Health and Human Services. The health benefits of smoking cessation. A report of the Surgeon General. Washington, DC, Department of Health and Human Services (US), Publication no. (CDC) 90-8416, 1990.

9 Mannino DM, Homa DM, Akimbani IJ. COPD surveillance - United States. MMWR 2002; 51: 3-16.

10 Lundback B, Lindberg A, Lindstrom M, et al. Not 15 but $50 \%$ of smokers develop COPD? Report from the Obstructive Lung Disease in Northern Sweden Studies. Respir Med 2003; 97: 115-122.

11 Rennard SI. Antiinflammatory therapies other than corticosteroids. Proc Am Thorac Soc 2004; 1: 282-287.

12 Di Stefano A, Turato G, Maestrelli P, et al. Airflow limitation in chronic bronchitis is associated with $\mathrm{T}$ lymphocyte and macrophage infiltration of the bronchial mucosa. Am J Respir Crit Care Med 1996; 153: 629-632.

13 O'Shaughnessy TC, Ansari TW, Barnes NC, Jeffery PK. Inflammation in bronchial biopsies of subjects with chronic bronchitis: inverse relationship of CD8+ T lymphocytes with FEV1. Am J Crit Care Med 1997; 155: 852-857.

14 Saetta M, Di Stefano A, Turato G, et al. CD8+ Tlymphocytes in peripheral airways of smokers with chronic obstructive pulmonary disease. Am J Respir Crit Care Med 1998; 157: 822-826.

15 Saetta M, Baraldo S, Corbino L, et al. CD8+ve cells in the lungs of smokers with chronic obstructive pulmonary disease. Am J Respir Crit Care Med 1999; 160: 711-717.

16 Peinado VI, Barbera JA, Abate $\mathrm{P}$, et al. Inflammatory reaction in pulmonary muscular arteries of patients with mild chronic obstructive pulmonary disease. Am J Respir Crit Care Med 1999; 159: 1605-1611.

17 Thompson AB, Daughton D, Robbins RA, Ghafouri MA, Oehlerking M, Rennard SI. Intraluminal airway inflammation in chronic bronchitis: characterization and correlation with clinical parameters. Am Rev Respir Dis 1989; 140: 1527-1537.

18 Saetta M, Turato G, Facchini F, et al. Macrophage and neutrophil infiltration in the bronchial glands of subjects with chronic obstructive pulmonary disease. Am J Respir Crit Care Med 1997; 155: A595.

19 Hogg JC, Chu F, Utokaparch S, et al. The nature of smallairway obstruction in chronic obstructive pulmonary disease. N Engl J Med 2004; 350: 2645-2653.

20 Saetta M, Di Stefano A, Maestrelli P, et al. Airway eosinophilia in chronic bronchitis during exacerbations [see comments]. Am J Respir Crit Care Med 1994; 150: 1646-1652.

21 Anthonisen NR, Connett JE, Kiley JP, et al. Effects of smoking intervention and the use of an inhaled anticholinergic bronchodilator on the rate of decline of FEV1. JAMA 1994; 272: 1497-1505.

22 Skold CM, Hed J, Eklund A. Smoking cessation rapidly reduces cell recovery in bronchoalveolar lavage, while alveolar macrophage fluorescence remains high. Chest 1992; 101: 989-995. 
23 Swan GE, Hodgkin JE, Roby T, Mittman C, Jacobo N, Peters J. Reversibility of airways injury over a 12-month period following smoking cessation. Chest 1992; 101: 607-612.

24 Turato G, Di Stefano A, Maestrelli P, et al. Effect of smoking cessation on airway inflammation in chronic bronchitis. Am J Respir Crit Care Med 1995; 152: 1262-1267.

25 Rutgers SR, Postma DS, ten Hacken NH, et al. Ongoing airway inflammation in patients with COPD who do not currently smoke. Thorax 2000; 55: 12-18.

26 Lapperre TS, Postma DS, Gosman MM, et al. Relation between duration of smoking cessation and bronchial inflammation in COPD. Thorax 2006; 61: 115-121.

27 Willemse BW, ten Hacken NH, Rutgers B, LesmanLeegte IG, Postma DS, Timens W. Effect of 1-year smoking cessation on airway inflammation in COPD and asymptomatic smokers. Eur Respir J 2005; 26: 835-845.

28 Spurzem JR, Romberger DJ, Manouilova LS, et al. Smoking cessation is followed by an increase in T lymphocytes recovered by bronchoalveolar lavage (BAL) in COPD. Proc Am Thorac Soc 2006; 3: A628.

29 Rennard SI. Clinical approach to patients with chronic obstructive pulmonary disease and cardiovascular disease. Proc Am Thorac Soc 2005; 2: 94-100.

30 Gan WQ, Man SF, Senthilselvan A, Sin DD. Association between chronic obstructive pulmonary disease and systemic inflammation: a systematic review and a metaanalysis. Thorax 2004; 59: 574-580.

31 Gan WQ, Man SF, Sin DD. The interactions between cigarette smoking and reduced lung function on systemic inflammation. Chest 2005; 127: 558-564.

32 Mannino DM, Buist AS, Petty TL, Enright PL, Redd SC. Lung function and mortality in the United States: data from the First National Health and Nutrition Examination Survey follow up study. Thorax 2003; 58: 388-393.
33 Sin DD, Wu L, Man SF. The relationship between reduced lung function and cardiovascular mortality: a populationbased study and a systematic review of the literature. Chest 2005; 127: 1952-1959.

34 Hole DJ, Watt GC, Davey-Smith G, Hart CL, Gillis CR, Hawthorne VM. Impaired lung function and mortality risk in men and women: findings from the Renfrew and Paisley prospective population study. BMJ 1996; 313: 711-716.

35 Ashley F, Kannel WB, Sorlie PD, Masson R. Pulmonary function: relation to aging, cigarette habit, and mortality. Ann Int Med 1975; 82: 739-745.

36 Sin DD, Man SF. Why are patients with chronic obstructive pulmonary disease at increased risk of cardiovascular diseases? The potential role of systemic inflammation in chronic obstructive pulmonary disease. Circulation 2003; 107: 1514-1519.

37 Eid AA, Ionescu AA, Nixon LS, et al. Inflammatory response and body composition in chronic obstructive pulmonary disease. Am J Respir Crit Care Med 2001; 164: 1414-1418.

38 Broekhuizen R, Wouters EF, Creutzberg EC, Schols AM. Raised CRP levels mark metabolic and functional impairment in advanced COPD. Thorax 2006; 61: 17-22.

39 Agusti AG, Sauleda J, Miralles C, et al. Skeletal muscle apoptosis and weight loss in chronic obstructive pulmonary disease. Am J Respir Crit Care Med 2002; 166: 485-489.

40 Rennard S. Defective repair in COPD: the American hypothesis. In: Pauwels RA, Postma DS, eds. Long-Term Intervention in Chronic Obstructive Pulmonary Disease. New York, Marcel Dekker, 2004; pp. 165-200.

41 Gashi AA, Borson DB, Finkbeiner WE, Nadel JA, Basbaum CB. Neuropeptides degranulate serous cells of ferret tracheal glands. Am J Physiol 1986; 251: C223-C229.

42 Rennard SI. Repair. In: Calverley PMA, MacNee W, Pride NB, Rennard SI, eds. Chronic Obstructive Pulmonary Disease. London, Arnold, 2003; pp. 139-150. 